\title{
Hydroponic Training to Improve Community Living Standards in Densely Populated and Weak Economies
}

\author{
Bob Foster $^{1}$, Fitriani Reyta ${ }^{2}$, Muhamad Deni Johansyah ${ }^{3}$ \\ ${ }^{1,2}$ Universitas Informatika dan Bisnis Bandung, Jawa Barat, Indonesia \\ ${ }^{3}$ Universitas Padjajaran Bandung, Jawa Barat, Indonesia \\ bobriset@unibi.ac.id
}

\begin{abstract}
Simple hydroponic technology plays a role in increasing human capacity and capacity to deal with the impacts of climate change and contribute to sustainable development. Dealing with the impacts of climate change means reducing significantly or eliminating negative effects on society and the natural environment, this activity can be started through simple things such as reforesting the immediate environment in the community. The principle of sustainable development is an important guide to ensure that the use of simple technologies such as hydroponics to reduce climate change by recycling materials also has an impact on increasing the ability of future generations to meet their own needs. I Green Project, We Grow Communityis a community service initiated by LPPM Universitas Informatics and Bisnis Indonesia in collaboration with the International Student Organization AIESEC focuses on the role of academics in mitigating climate change by adopting actions to mitigate the impacts of climate change. Because climate and environment are interrelated, this community service also considers the role of hydroponics as greening the environment in helping individuals understand the environment around them, which is a prerequisite for overcoming the problem of climate change. Pengabdian located in Baranang Siang, Bandung City, West Java, 2018 has provided an understanding of the steps needed to reduce climate change, including several policy issues that need to be addressed, changing environmental conditions to be greener and activating community participation to have additional income from the program. Hydroponics so that people with weak economies are more helped to be independent. This program is implemented for 1 month in August with the number of community members as executors of 30 (thirty) people.
\end{abstract}

Keywords

hydroponics, green environment; improvement of living standards, empowerment

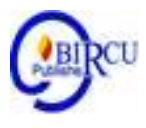

\section{Introduction}

Climate change is described as: changes in climatic states that can be identified (eg by means of statistical tests) by changes in their mean and / or variability, and occur over a long period of time, usually decades or more. Research shows that climate change can result in shifts in temperature and rainfall, some both and others a challenge to the environment, livelihoods, health, and the frequency and intensity of climate-related natural disasters such as floods and landslides. Climate change is associated with greenhouse gas (GHG) emissions. The two main sources of greenhouse gas emissions come from: 1) burning fossil fuels (e.g. coal, petroleum, natural gas), and 2) removing carbon sinks in nature. 
Responses to climate change call for actions that will help individuals and societies adapt to the climate impacts of environmental change or mitigate the amount of greenhouse gases released into the atmosphere. Green Growth is an additional approach to development that has the potential to combine the goals of climate change adaptation, climate change mitigation and economic growth. Adaptation to climate change requires countries to change their behavior in order to reduce "the vulnerability of natural and human systems to the perceived or perceived impacts of climate change." Governments and organizations can adapt to climate change by preparing to change environmental and climatic conditions, before all impacts are felt by society, certain groups, the environment and the ecosystem. The World Wide Fund for Nature (WWF) has identified two priorities for adaptation. Establishment of a "worldwide early warning system and development support for poor countries to gain access to drought-resistant crops." Adaptation measures are especially important for developing countries because they have to deal with the direct impacts of climate change. Many of the world's poorest populations are in developing countries, so they are most at risk from climate change, and in general their capacity to deal with disasters and climate change is limited.

Adaptation to climate change requires the following: 1) A good understanding of the natural environment and how it is challenged and altered by climate change over time and space and how these changes will affect natural and human ecosystems. 2) ICT is indispensable for environmental observation, analysis, planning, management and monitoring, which can help policy makers formulate decisions regarding climate change adaptation actions. 3) Helping vulnerable communities adapt to the realities and projections of climate change. This includes improving livelihoods so that people are less at risk from climate change (eg by modifying agricultural practices). Part of this preparedness also involves preparing populations and communities for dealing with more frequent disasters and extreme weather and related events. ICTs are widely used in all phases of the DRM (Disaster Risk Management) cycle. 4) Building organizational capacity in dealing with climate change will increase the independence of local communities and organizations in learning, planning and adapting to climate change. Forest and biodiversity conservation, sustainable land use management, disaster early warning and promotion of awareness and capacity building are essential for adaptation (Supriyadi, 2019). 4) Building organizational capacity in dealing with climate change will increase the independence of local communities and organizations in learning, planning and adapting to climate change. Conservation of forests and biodiversity, sustainable land use management, disaster early warning and promotion of awareness and capacity building are central to adaptation (Supriyadi, 2019). 4) Building organizational capacity in dealing with climate change will increase the independence of local communities and organizations in learning, planning and adapting to climate change. Forest and biodiversity conservation, sustainable land use management, disaster early warning and promotion of awareness and capacity building are essential for adaptation (Supriyadi, 2019).

The current healthy lifestyle has motivated farmers to prioritize the quality of their crops to meet consumer needs. There is limited land for agriculture, especially in densely populated cities, land that is not fertile due to pollution is also a barrier for farmers. Meanwhile agricultural commodities in Indonesia are expected to meet the needs of domestic consumers and have a great opportunity to export abroad so that farmers must have alternatives in techniques agricultural cultivation (Thiyagarajan et al, 2007). Turner (2012) states that hydroponics is the cultivation of plants that only use water and do not use soil as a planting medium. The hydroponic system can be used as a solution for modern crop cultivation and can be applied by farmers who have problems in the shortage of agricultural land because hydroponics can be used in narrow land conditions. Hydroponic systems that use planting media in the form of water with proper nutrition and controlled $\mathrm{pH}$ can be 
applied to plants whose fertilization or sprouting process takes place in a short time. Therefore, not all plants are ideal when planted with a hydroponic concept.

Hydroponic techniques are mostly carried out on a small scale as a hobby among Indonesians. However, farmers can use this system by paying attention to what types of plants will be cultivated on a commercial scale, because not all agricultural products have economic value, be they vegetables, fruits or ornamental plants. Several types of hydroponic plants that have high economic value in agricultural commodities such as green leafy vegetables, namely lettuce, spinach, kale, mustard greens, cucumbers and fruits such as tomatoes, melons, strawberries, grapes or other types such as cucumbers, chilies and peppers. Hydroponic work is relatively easy because it does not require a lot of money like other conventional planting techniques. There is efficiency of the labor of the farmers and if the farmers run this system with intensive care, the plants will grow faster and provide sustainable production results so that the quantity and quality of hydroponic agricultural production can be more guaranteed. The hydroponic cultivation process is usually environmentally friendly and safe for consumption because it uses components that are free from contamination of harmful microorganisms and pesticides and there is more intensive control from farmers in controlling pests and diseases (Turner, 2012).

\section{Review of Literatures}

The word "hydroponics" comes from the Greek words for "water" and "labor," and refers to the technique of growing plants without soil. To some, the concept might sound counterintuitive, but hydroponics is a unique, sustainable way to grow delicious and healthy crops. When plants are grown hydroponically, their roots are dipped directly into nutrientrich solutions. Since they are connected directly to the necessary nutrients, hydroponicallygrown plants have smaller root systems. This saves energy and allows it to be diverted to leaf and stegrowth. The nutrient-rich solutions also help plants grow much faster than they would if they were grown traditionally, and hydroponics often results in greater crop yields than conventional methods. Additionally, since hydroponic methods do not rely on soil, it also decreases the risk of pests and soilborne diseases, leading to healthy crops that you'll feel good about growing and eating.

Hydroponics allows for year-round growth of crops like lettuce, herbs, tomatoes, and strawberries, and work in limited spaces, like a windowsill or rooftop garden. With high yields, healthy methods, and sustainable systems that require minimal space, hydroponics is an ideal fit with Thrive Living Communities. Picnics with neighbors or community dinners will feel even better knowing that your food is fresh, healthy, and grown right in your neighborhood.

Hydroponic Agriculture can be one of the solutions to solve the problem of agricultural land. Hydroponics comes from the word hydro which means water and ponic which means workmanship, so hydroponics can be interpreted as a technique of plant cultivation using planting media other than soil and utilizing water to channel nutrients needed to each plant (Lingga, 1985). Hydroponics also has several advantages including the cultivation that does not depend on climate, continuous crop yields, and more practical plant care, commodities that are often cultivated with hydroponics are horticultural commodities. Horticulture commodities have a short harvesting age and small morphology so that they are easily cultivated hydroponically. This reason is why hydroponics can be one of the cultivation techniques suitable for water spinach (Lingga in Andrian et al, 2019). 
Agricultural land is increasingly narrow due to the shifting of the function of agricultural land into industrial areas, so that hydroponic cultivation is considered appropriate to utilize available land because this cultivation system does not require soil media. The hydroponic system uses a variety of planting media other than soil, among others, with media such as fuel husk, husk, sand, zeolite, rockwoll, peat (peat moss) and coconut husk powder (Prihmantoro and Indriani in Zailani et al, 2020).

Hydroponic cultivation can provide more benefits than traditional farming systems. The advantages that can be obtained include: harvested when really cooked, can be done close to the market or consumers, does not depend on the season and can be adjusted to the high market demand, guaranteed optimal growth climate because the environment is controlled, there is no problem with the land because it does not use soil media, safer because of handling biological pests and diseases, high quality results will be accepted by consumers at high prices so as to provide high profits as well (CropKing Inc in Zailani et al, 2020).

\section{Hydroponic System and Improvement of Living Standard of Weak Economic Community}

In 1929, William Frederick Gericke of the University of California at Berkeley began to publicly promote solution culture used to produce agricultural crops. At first he called it the term aquaculture (or in Indonesia it is called aquaculture), but later found out that aquaculture has been applied to aquaculture. Gericke created a sensation by growing a tomato, stretching twenty-five feet high, in his backyard with a solution of mineral nutrients other than soil (Thiyagarajan et al, 2007).

This NFT system is the most popular way in terms of hydroponics. This NFT system continuously circulates dissolved nutrients in water without using a timer for the pump. These nutrients flow into the gully through the plant roots and then return to the water reservoir, and so on. Advantages of hydroponic techniques

1) Does not require land

2) Water will continue to circulate in the system and can be used for other purposes, such as an aquarium

3) Nutrition control is simpler so that nutrients can be provided more effectively and efficiently

4) Relatively not polluting nutrients to the environment

5) Provides more yield and plants grow faster

6) Easy to harvest the results

7) Sterile and clean

8) Planting media can be used repeatedly

9) Free from weeds

Various types of plants that can be planted hydroponically:

1) Types of hydroponic vegetables include Pokcoy, mustard greens, spinach, kale, kailan, lettuce, celery and others.

2) Types of fruit include cucumbers, melons, chilies, tomatoes, eggplants and others.

3) Types of herbal plants such as mint, basil, coriander, and others.

4) Types of flower plants such as orchids and roses 


\section{Result and Discussion}

Table 1. Material Tools required
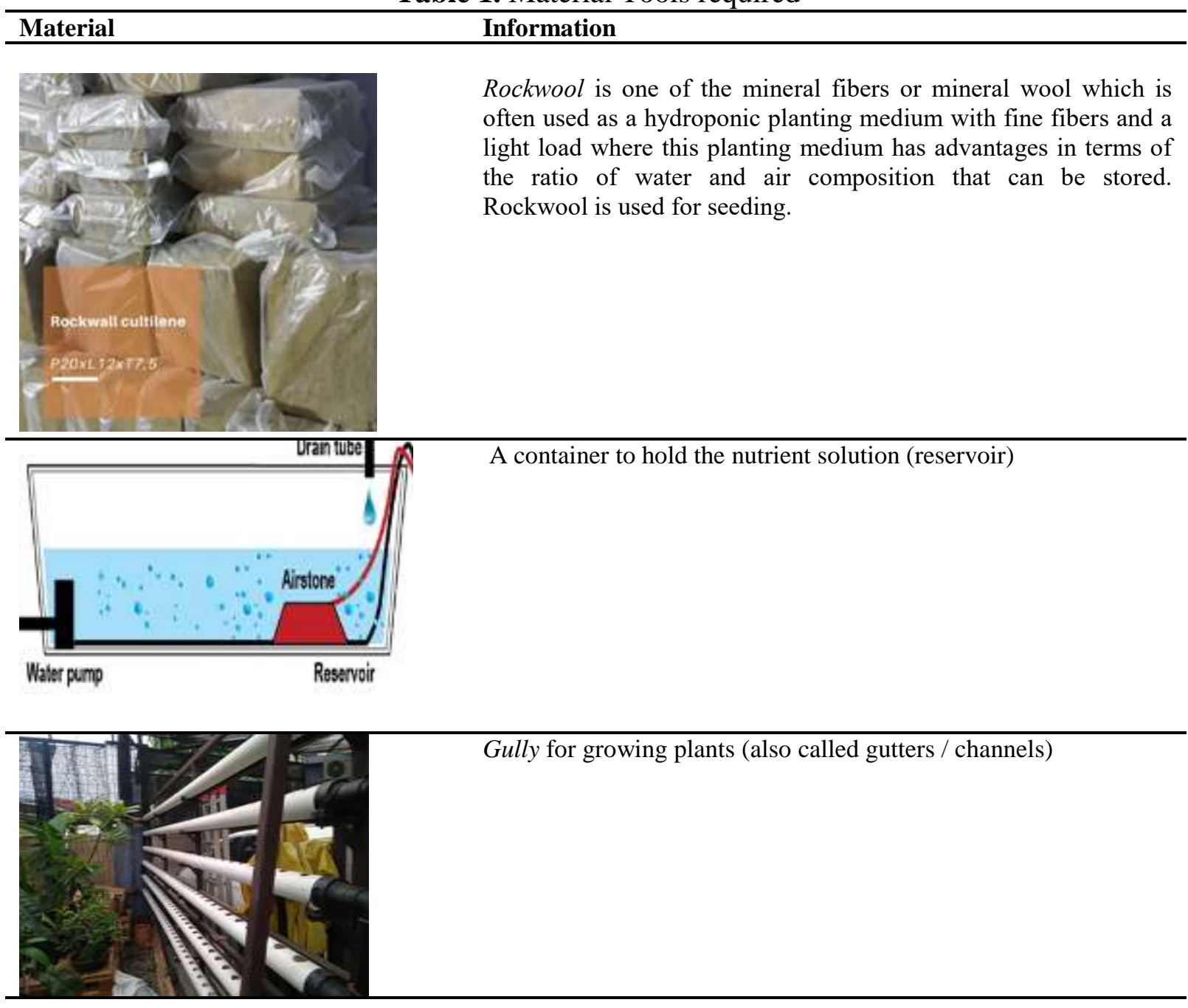

\begin{tabular}{ll}
\hline Material & Information \\
\hline & $\mathrm{PH}$ meter, as a measure of plant $\mathrm{PH}$ \\
\hline
\end{tabular}



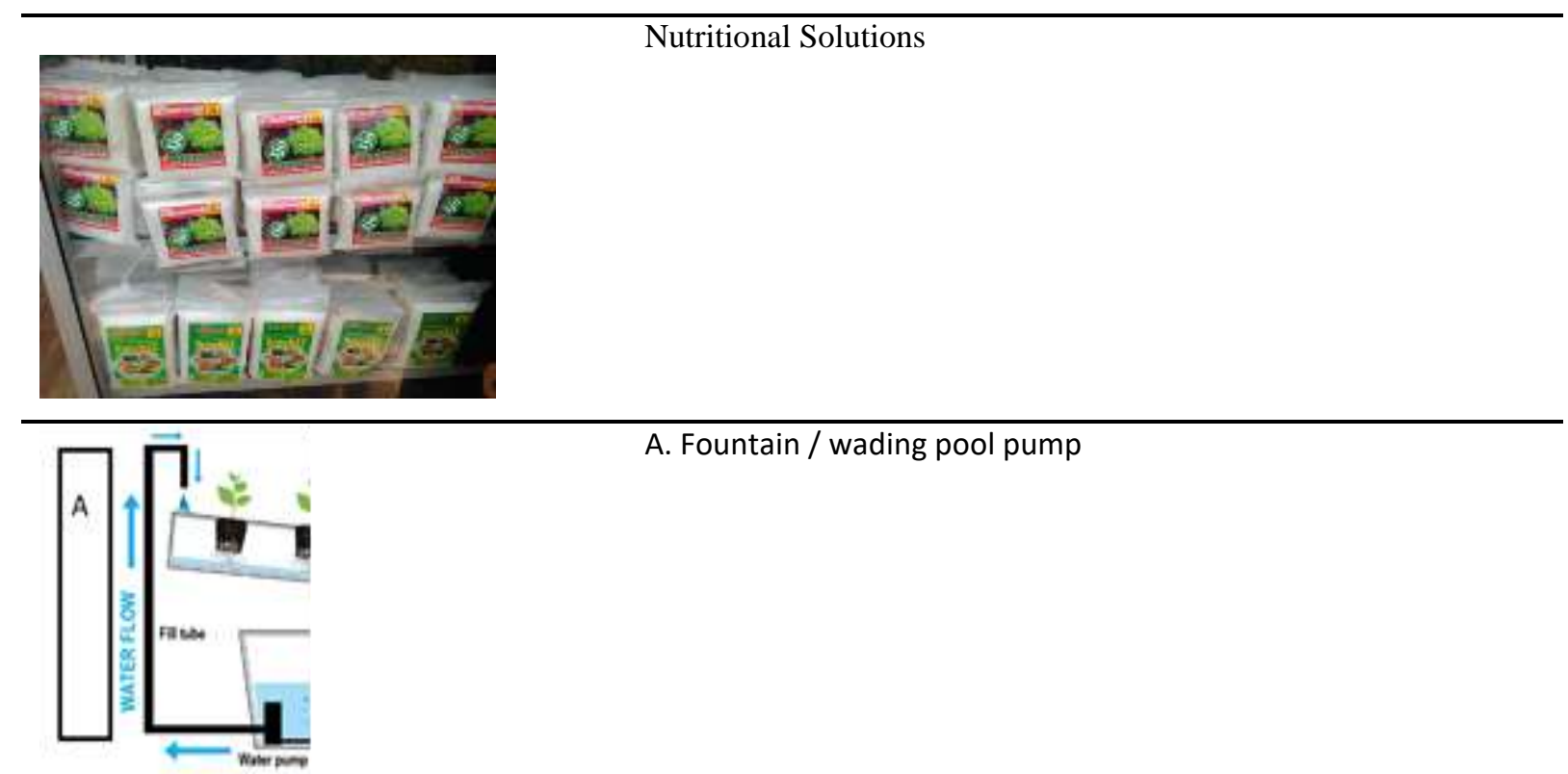

A. Fountain / wading pool pump

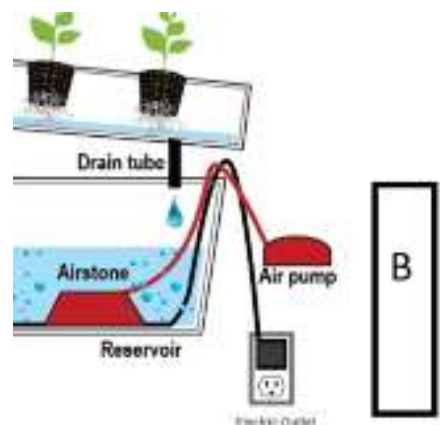

B. Tubing to distribute water from pump to gully NFT plant premises

Return system (tubing, channel) to drain the used nutrient solution back to the reservoir 
Table 2. NFT System Process

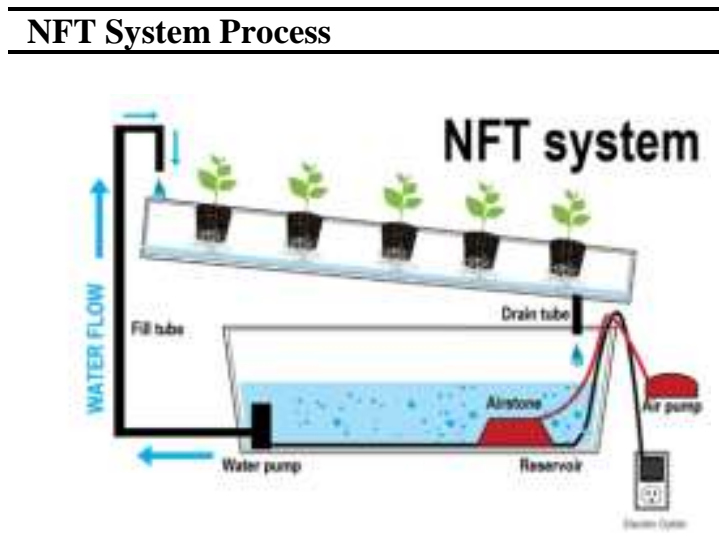

Information

The nutrient solution is pumped from the reservoir, usually to the manifold that connects the larger tube to a number of smaller ones. Each of these smaller tubes drains the nutrient solution to one side of the respective gully with the plant inside.

A thin layer (film) of the nutrient solution flows through each channel with the plants in it to the other side, passing through each plant and wetting the roots at the bottom of the canal as it happens. The nutrient solution flows from side to side because the channel is slightly tilted so the water flows down an inclined surface.

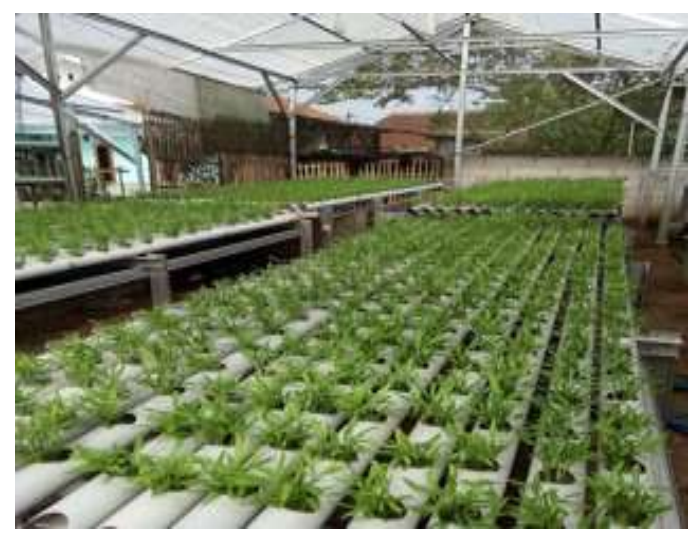

Plants in a gully are usually placed over water by placing seed starting in a small one-inch rockwool or planting medium into the small hole at the top of the gully. The roots of the seedlings are flooded at the bottom of the tube / canal where the roots get nutrients from a shallow stream of a flowing nutrient solution. The excess nutrient solution flows out from the bottom end of each drain into another channel or tube, and is redirected back to the reservoir where it is recirculated through the system.

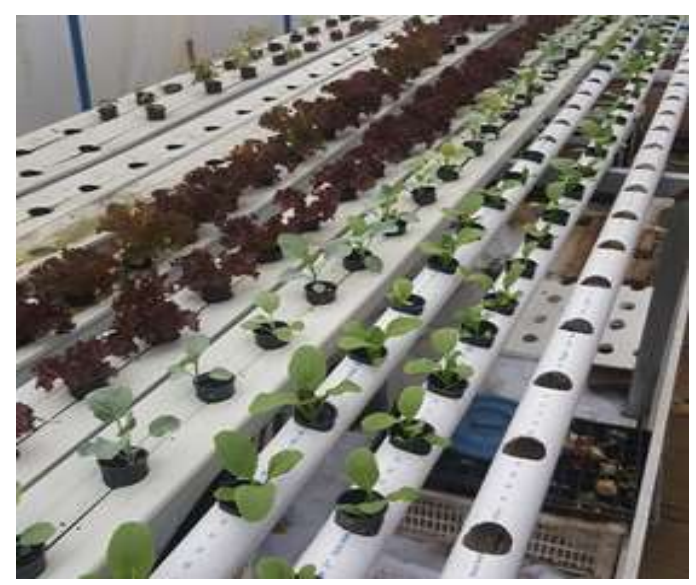

Stages in the NFT system:

- Module creation

- Seeding

- Transfer of seedlings from seedling trays to modules

- Transfer from the module after seedling to the maturity

module

- Harvesting

- Cleaning / sterilizing the module if it has been several times

harvest avoid pests or pathogens that can be harmful 
Table 3. Results of Hydroponic Farming Using the NFT system

\begin{tabular}{l} 
Production result \\
$\begin{array}{l}\text { Hydroponic plants tend to be more attractive and clean and the } \\
\text { structure of the plants is more attractive than conventional, tastes } \\
\text { better and the texture is more crispy when consumed because plant } \\
\text { nutrients are regulated by the farmers themselves, yields are faster } \\
\text { than conventional, but hydroponic plants tend to be more fragile. } \\
\text { with a high water content compared to conventional }\end{array}$ \\
\hline
\end{tabular}

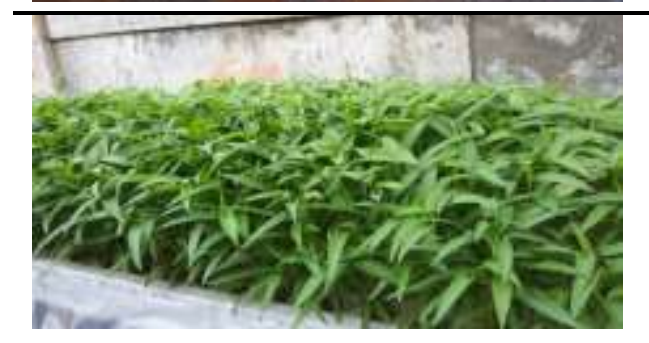

Plant growth tends to be better, because the oxygen intake is greater and the water temperature tends to be lower so that the absorption of nutrients is maximized and the harvesting age of the plants is faster and more vigorous.

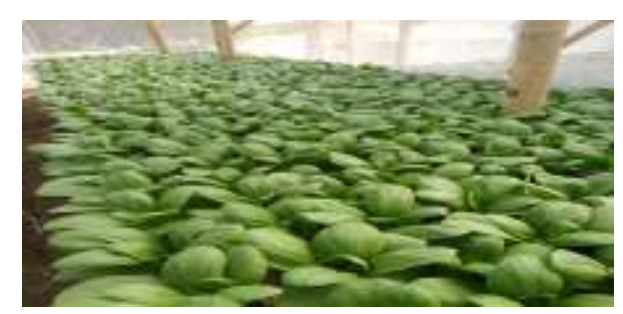

Agricultural commodities produced can be of various types except hard plants and are large in shape, so other commodities are very potential in terms of business in agricultural commodities because their production results are more natural and are faster in processing so that they can meet the needs of the community.

\section{Conclusion}

Based on this community service, it can be concluded that the hydroponic farming system provides opportunities for people in a weak economic environment to be able to increase their productivity with a narrow area of land to produce the vegetables they produce and have income to increase income and consume healthy food so that nutrition improves Hydroponic farming can produce yields in a shorter time, namely 15-21 days and more than using conventional systems. The quality of the produce produced is also very good and natural because it does not use pesticides so that it is more environmentally friendly, uses nutrient solutions for fertilizer efficiency, water as a planting medium.

These quality yields can meet market needs for community consumption of natural vegetables. Farmers can sell hydroponic farming products at a higher selling price than conventional ones so that the welfare index of farmers increases, which is shown by data from BPS that there is an increase in the Farmers Exchange Rate (NTP) nationally, an increase of 0.58 percent in August 2019 of 103.22 compared to the previous month which was 102.64. The increase in NTP this time was due to the increase in the index of prices received by farmers by 0.69 percent, higher than the increase in the index of prices paid by farmers of 0.11 percent which was influenced by the increase in NTP in the four agricultural sub-sectors. With the use of the NFT Hydroponics system. 
Suggestions for further service are expanded service locus, longer community service time, and explore other techniques of hydroponic farming systems that are more cost-efficient so that they can become input for people who want to innovate in farming systems at a more economical cost but still be able to produce quality crops.

\section{References}

Andrian, D. et al. (2019). The Use of Liquid Organic Fertilizer As Growth Media and Production of Kangkung (Ipomoea reptans Poir) Hydroponics. Budapest International Research in Exact Sciences (BirEx) Journal. P. 23-34.

Bambi Turner. (2012). "How Hydroponics Works," HowStuffWorks.com. Retrieved: 29-052012.

Desyinta Nuraini - Bisnis.com 03 September. (2019). Ministry of Agriculture Calls BPS Data Evidence of Improving Farmer Welfare

G. Thiyagarajan, R. Umadevi \& K. Ramesh, "Hydroponics," Science Tech Entrepreneur, (January 2007), Water Technology Center, Tamil Nadu Agricultural University, Coimbatore, Tamil Nadu 641 003, India.

Supriyadi, Indarto Happy. et al. (2019). Adaptation to the impacts of climate change on Coastal Communities. LIPI Journal. ISBN: 978-602-6504-27-2.

Zailani, M. et al. (2019). Gowth Response and Crop Production (Brassica Juncea L.)Against Watering Time Interval at Various Hydroponics Media. Budapest International Research in Exact Sciences (BirEx) Journal. P. 9-22 